\title{
DIREITO FINANCEIRO APLICADO AO SETOR DO PETRÓLEO
}

\author{
Tese de Doutorado exigida para a obtenção do \\ título de Doutor no Programa de Pós- \\ graduação Stricto Sensu em Direito Financeiro \\ da Universidade de São Paulo \\ Orientador: José Maurício Conti
}

Faculdade de Direito da Universidade de São Paulo

São Paulo

2013 


\title{
DIREITO FINANCEIRO APLICADO AO SETOR DO PETRÓLEO
}

\author{
Tese de Doutorado exigida para a obtenção do \\ título de Doutor no Programa de Pós- \\ graduação Stricto Sensu em Direito Financeiro \\ da Universidade de São Paulo \\ Orientador: José Maurício Conti
}

Faculdade de Direito da Universidade de São Paulo

São Paulo

2013 


\section{DIREITO FINANCEIRO APLICADO AO SETOR DO PETRÓLEO}
APROVADA:
de de

Tese de Doutorado exigida para a obtenção do título de Doutor no Programa de Pósgraduação Stricto Sensu em Direito Financeiro da Universidade de São Paulo
Professor José Maurício Conti
(Orientador - FDUSP)

Professor

Professor

Professor

Professor 


\section{DEDICATÓRIA}

Aos meus avós queridos, Luci e Hélio. 


\section{AGRADECIMENTOS}

Antes, e acima de tudo, a Deus, meu pai amado, por tudo que tenho e por tudo que sou, por ter concedido tantas bênçãos em minha vida;

Aos meus avós Luci e Hélio, por todo o amor e carinho;

Aos meus avós Lindalva e José, pelo exemplo de firmeza e retidão;

A minha mãe, Mônica, por todo o seu amor, pelo exemplo de coragem e determinação;

Ao meu pai, Silvio, pelo exemplo de otimismo e perseverança;

Aos meus irmãos Heloíza e Arthur, pela cumplicidade;

Ao meu orientador José Maurício Conti, exemplo de caráter e seriedade no trabalho e na vida, agradeço pela confiança depositada neste trabalho e pelos ensinamentos;

Aos meus queridos amigos que contribuíram para a realização desta tese e fizeram de São Paulo um lugar tão prazeroso de se viver: André, Basile, Cecília, Celso, Dalton, Fred, Gabriel, Gustavo, Irineia, Maysa e Michel. Obrigada pelas divertidas conversas jogadas fora e pelo compartilhamento de tantos sonhos;

Aos meus primos queridos, Rodrigo, Alessandra e Thaysa;

A meus tios Gaudêncio e Verydiana, por todo o apoio;

A Jing e Karla, amigas eternas;

Agradecemos também o apoio financeiro para a realização deste estudo concedido pela Fapesp e pelo CNPQ. 


\section{RESUMO}

Busca-se, por meio da presente tese, rever a natureza jurídica atribuída aos royalties do petróleo pela doutrina majoritária no Brasil, que os caracteriza como um preço público devido pelas companhias petrolíferas à União, em contraprestação a um direito de exploração de bem público, do qual este ente político detém a propriedade.

Intenta-se demonstrar que se trata, na verdade, de um pagamento realizado em contraprestação à alienação de um bem público (o petróleo) ao particular, o que traz consequências profundas à forma como tais receitas serão classificadas na Lei Orçamentária Anual dos três entes federativos, bem como ao grau de restrição a sua aplicação.

Aceita essa posição, os royalties passarão a ser classificados nas Leis Orçamentárias como receitas de capital, fruto da alienação de um bem público, e não mais como uma receita corrente patrimonial, decorrente da exploração de um bem público.

Assim, uma vez classificados como receitas de capital, somente poderão ser aplicados em despesas de capital, ou seja, basicamente em investimentos e inversões financeiras, de acordo com o artigo 44 da Lei de Responsabilidade Fiscal, ficando vedada a possibilidade, tal qual tem sido feito, de serem utilizados no custeio da máquina pública, aplicação contrária a uma lógica de uso sustentável dessas receitas.

Palavras-chave: royalties, natureza jurídica, Lei Orçamentária Anual, receitas de capital e investimentos. 


\begin{abstract}
The objective of this thesis is to review the nature of royalties given by the majority doctrine in Brazil, which characterize it as a public price payable by oil companies to the Union, in consideration of a right to explore a public good.

We aim to demonstrate that it is actually a payment made in consideration for the sale of a public good (oil), which has profound consequences on how such revenues shall be classified in the Annual Budget Law of the three political entities in Brazil (Union, states and municipalities), as well as the degree of restriction to their application.

Accepted our position, the royalties will be classified in Budgetary Laws as capital revenue, resulting from the sale of a public asset and not as a current revenue, due to an use of a public good.

So, once classified as a capital revenue, royalties may only be used in capital expenditures, like investments, in accordance with Article 44 of the Fiscal Responsibility Law, not in current expenditures that represents an application contrary to the logic of sustainable use of these revenues.
\end{abstract}

Keywords: royalty, Annual Budget Law, capital revenue and investments. 


\section{SUMÁRIO}

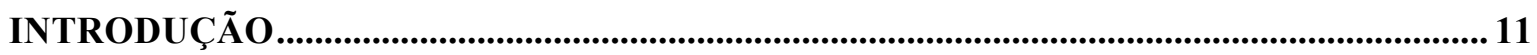

1 DO EXERCÍCIO DA SOBERANIA SOBRE OS RECURSOS NATURAIS NO

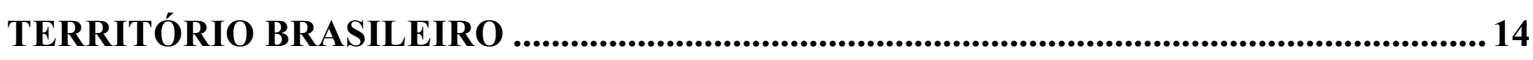

1.1 Considerações sobre o Princípio da Soberania dos Recursos Naturais no Direito

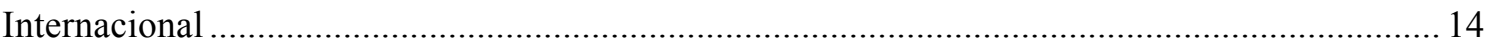

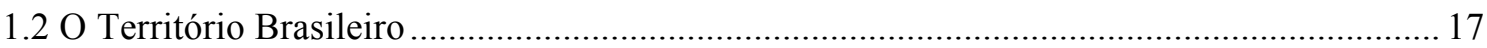

1.3 Do Exercício da Soberania sobre os Recursos Naturais da Plataforma Continental Brasileira

2 A PROPRIEDADE DO PETRÓLEO NO BRASIL .25

2.1 Considerações Gerais sobre o Exercício do Direito de Propriedade pelo Estado: bens do

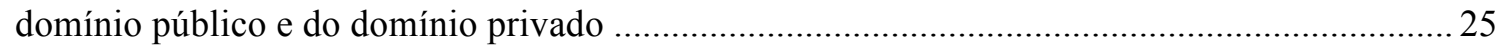

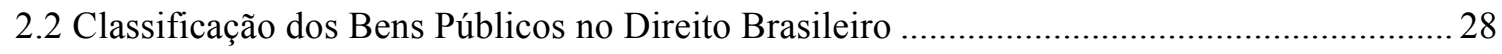

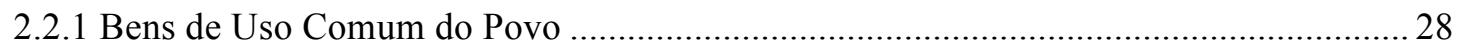

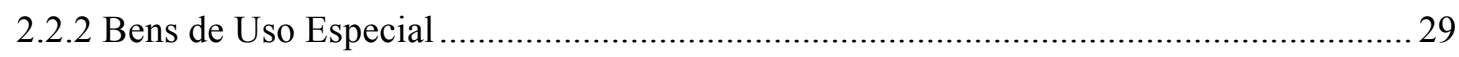

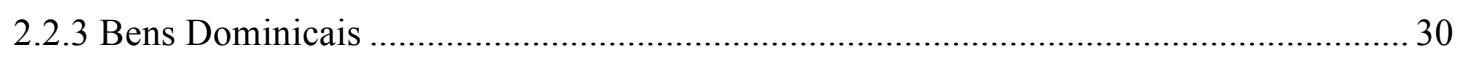

2.3 Do Regime Jurídico Aplicável ao Petróleo como Bem Público no Direito Brasileiro............ 32

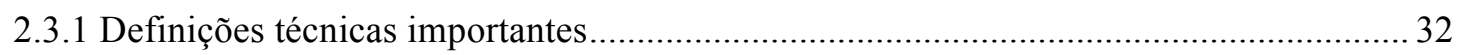

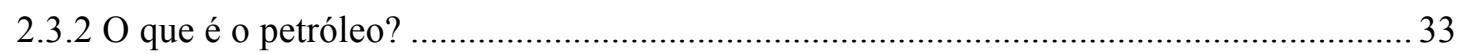

2.3.3 Outras definições importantes: reservatórios, jazidas, blocos e campos ..........................36

2.3.4 Da propriedade do petróleo no Direito brasileiro ............................................................. 39

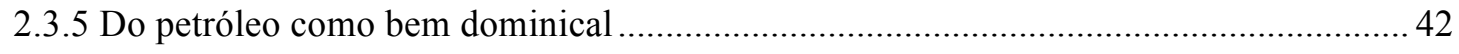

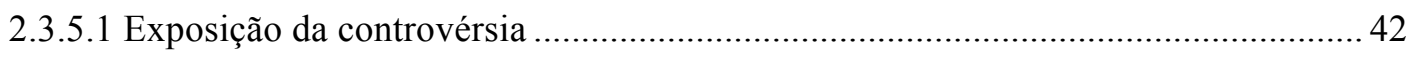

2.3.5.2 Do petróleo como bem de uso especial ................................................................. 43

2.3.5.3 Da caracterização do petróleo como bem dominical. Motivo 1: o atributo da alienabilidade

2.3.5.4 Da caracterização do petróleo como bem dominical. Motivo 2: permanência da interesse coletivo antes, durante e após a sua alienação ao particular .................................. 48

3 CONTRATOS DE EXPLORAÇÃO E PRODUÇÃO DE PETRÓLEO....................................52

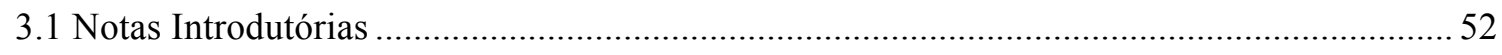

3.2 Da impossibilidade de se falar em concessão de uso de bem público no caso do petróleo: considerações acerca do objeto dos contratos de exploração e produção deste recurso 53

3.3 Da impossibilidade de se falar em concessão para o exercício de uma atividade econômica

Error! Bookmark not defined. 
3.4 Dos modelos contratuais para exploração e produção de petróleo utilizados na prática internacional

3.5 Modelos contratuais constitucionalmente autorizados no Brasil para as atividades de E\&PError! Bookmar

3.6 Contratos de Exploração e Produção de Petróleo no Brasil ......................................................... 77

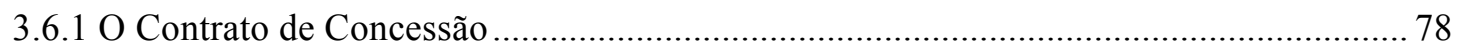

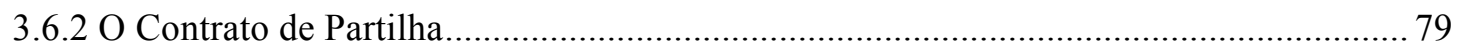

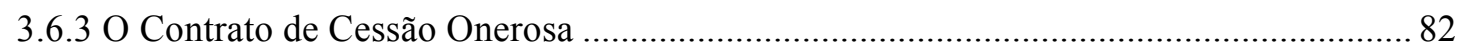

4 DA RECEITA PÚBLICA ORIUNDA DA ALIENAÇÃO DO PETRÓLEO NO BRASIL.. 90

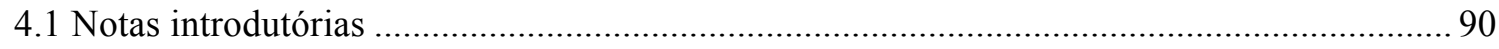

4.2 Da receita obtida por meio de contrato específico de compra e venda de petróleo ................ 90

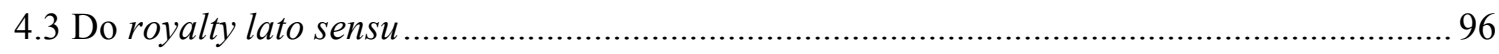

4.3.1 Espécies de royalties petrolíferos no Brasil: regramento jurídico e elementos constitutivos

4.3.1.1 Royalty do contrato de concessão - RCC

Error! Bookmark not defined.

4.3.1.2 Royalty sobre grande volume ou rentabilidade do contrato de concessão: participações especiais - PE .......................................................................................... 104

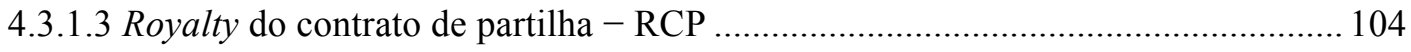

4.3.1.4 Royalty do Contrato de Cessão Onerosa - RCCO.................................................. 105

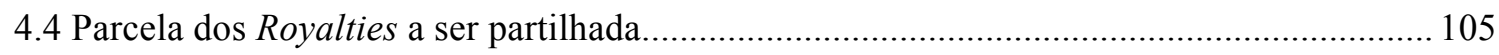

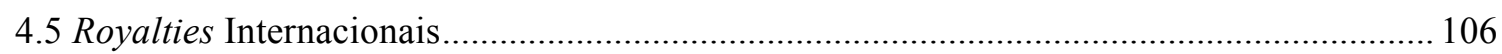

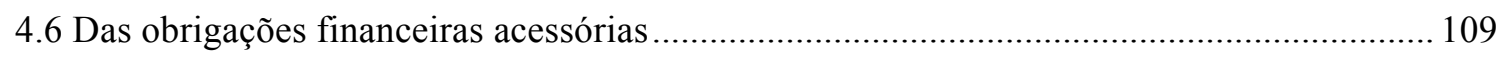

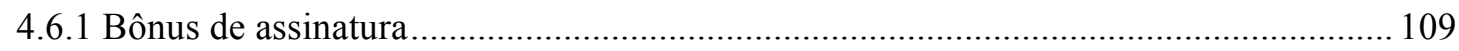

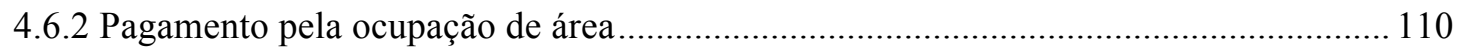

\section{CLASSIFICAÇÃO DAS RECEITAS PETROLÍFERAS NA LEI ORÇAMENTÁRIA}

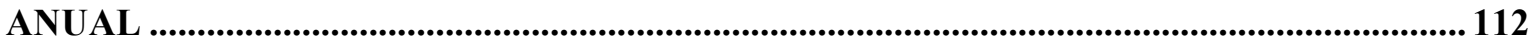

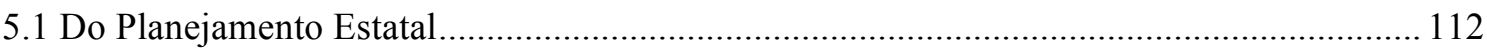

5.2 Leis de Planejamento da Ação Governamental: PPA, LDO e LOA ...................................... 112

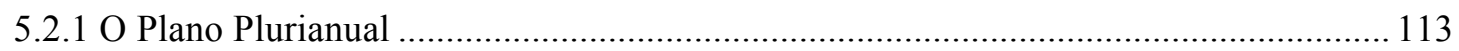

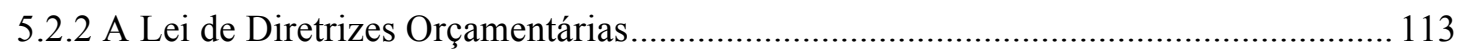

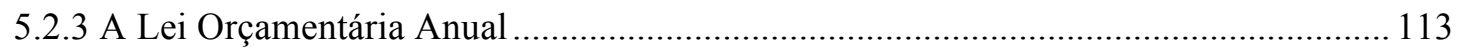

5.3 Definição de Receita para fins de Classificação na LOA........................................................ 114

5.4 Primeiro Nível de Classificação Orçamentária: classificação quanto à categoria

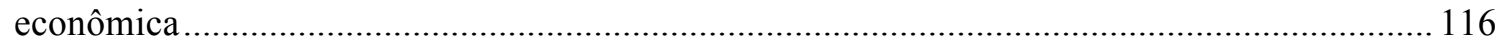

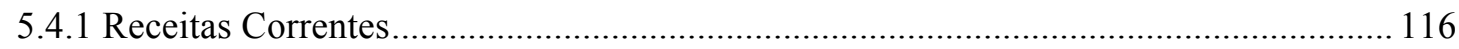

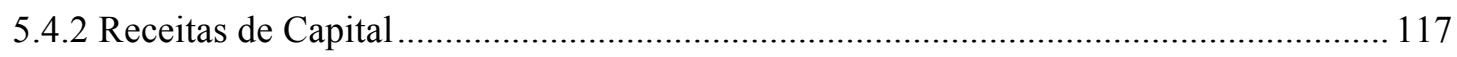

5.5 Segundo Nível de Classificação Orçamentária: Classificação quanto à origem ................... 119 
5.5.1 Considerações gerais 119

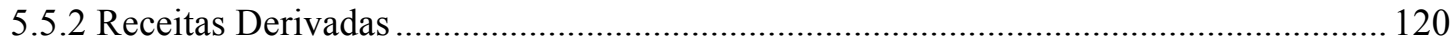

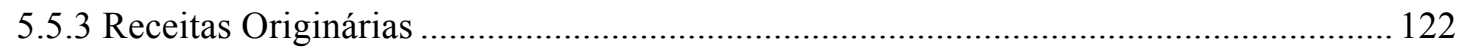

5.5.4 Operações de crédito, amortização de empréstimos e alienação de bens ....................... 123

5.5.5 Receitas Transferidas Correntes e de Capital.................................................................. 124

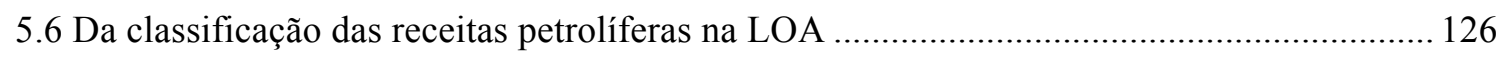

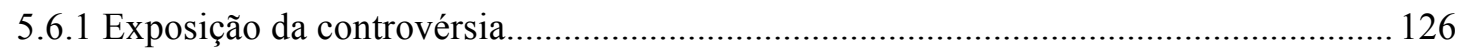

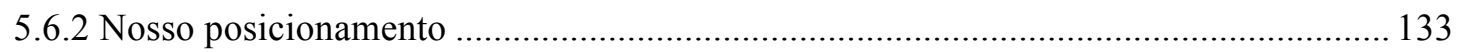

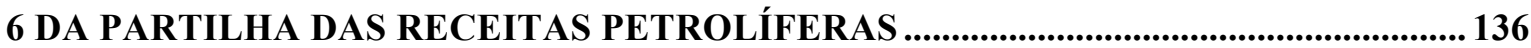

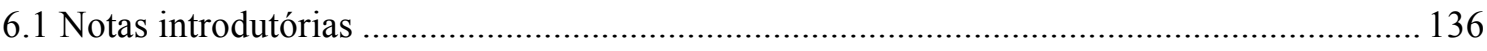

6.2 Federalismo Fiscal e Partilha de Receitas oriundas de recursos naturais .............................. 136

6.3 Exposição do debate político no Brasil sobre a partilha dos royalties .................................. 142

6.4 Regras de Repartição de Receitas Petrolíferas no Brasil....................................................... 147

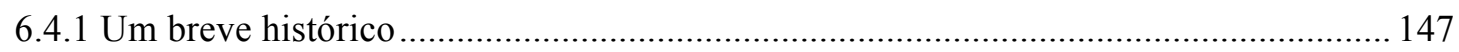

6.4.2 O que diz o parágrafo $1^{\circ}$ do artigo 20 da Constituição Federal?................................... 149

6.4.2.1 Quais são os sujeitos da relação jurídica regulada no parágrafo primeiro do

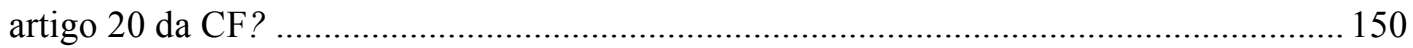

6.4.2.2 Quem são os beneficiários eleitos pela Constituição? ............................................ 151

6.4.2.3 Por que órgãos da Administração Direta da União? ................................................. 156

6.4.2.4 Qual a diferença entre participação e compensação? ............................................. 157

6.4.2.5 Parcelas de todas as receitas arrecadadas com a atividade petrolífera devem ser

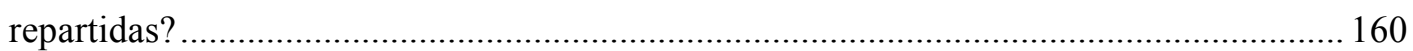

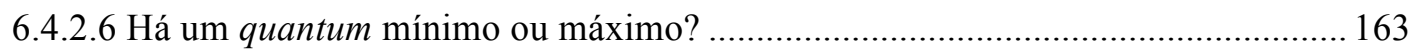

6.4.3 Critérios de repartição especificados na legislação ordinária............................................. 164

7 DAS REGRAS SOBRE A APLICAÇÃO DAS RECEITAS PETROLÍFERAS.....................173

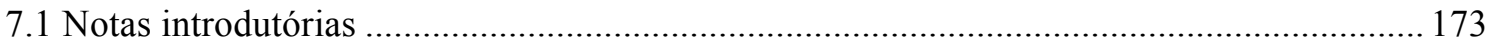

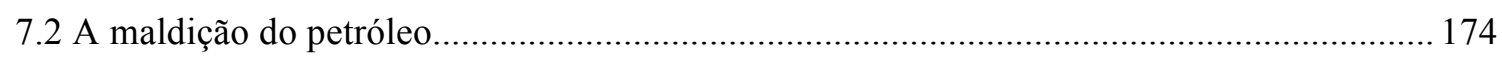

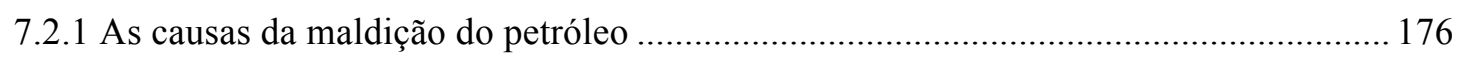

7.2.2 Medidas criadas para conter a maldição ….................................................................. 179

7.3 Regras de limitação ao uso das receitas petrolíferas no Brasil............................................. 182

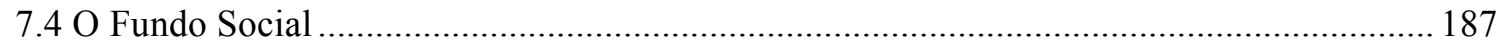

7.5 Da limitação do gasto das receitas petrolíferas decorrente da mudança de interpretação

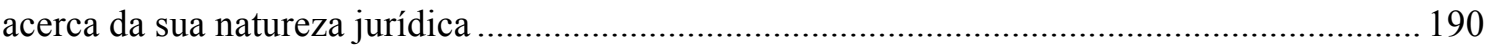

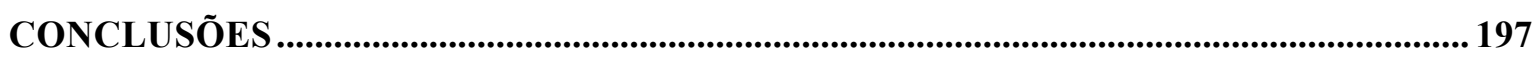

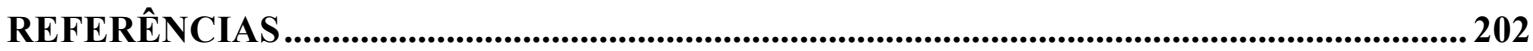




\section{INTRODUÇÃO}

A presente tese tem por objetivo rever a natureza jurídica atribuída aos royalties do petróleo pela doutrina majoritária no Brasil, que os caracteriza como um preço público devido pelas companhias petrolíferas à União, em contraprestação a um direito de exploração de bem público, do qual este ente político detém a propriedade.

O termo exploração, nesse contexto, refere-se a uma das duas espécies de contrato de concessão para uso de bem público existentes no direito administrativo pátrio: a concessão para simples uso e a concessão para exploração de bem público. Nesta última, além do simples uso que caracteriza a primeira, confere-se também um poder de gestão dominial, em que é possível haver a apropriação de parcelas do bem público por parte do contratado. Por exemplo, aquele que usa um rio para navegação estaria realizando um simples uso de bem público, contudo, se parte da água for retirada para uso industrial, não haveria apenas uso do rio, mas a apropriação de parte dele. Esse é o raciocínio que, indevidamente, é aplicado de maneira geral ao petróleo.

Como será visto no decorrer deste estudo, a concepção de que o proprietário do petróleo concede a outrem um direito de uso do recurso - e, consequentemente, as rendas obtidas por ele corresponderiam a uma contraprestação pela atribuição desse direito - tem origem nas lições do economista David Ricardo. Para este as rendas pagas aos donos das minas seriam decorrentes "do uso das forças originais e indestrutíveis do solo" (1996, p. 49).

A tese de Ricardo foi criticada pelo economista Alfred Marshall, pois tais rendas representariam uma contraprestação à alienação de parcelas da mina, não ao seu uso, o que seria impossível de se verificar na prática, conforme afirma, tendo em vista que a extração dos recursos extinguiria gradualmente a própria mina ${ }^{1}$.

Em nossa visão, os royalties do petróleo constituem, na linha dos ensinamentos de Marshall, um preço pago em contraprestação à alienação do petróleo, pela União, a uma empresa contratada para o exercício das atividades de exploração e produção.

Essa é a tese que se busca defender, demonstrando, em seguida, as consequências dessa alteração de paradigma para o Direito Financeiro.

\footnotetext{
${ }^{1}$ Ao se referir às rendas provenientes da agricultura, afirma que "esse rendimento é parte de uma renda constantemente repetida, enquanto a produção das minas é meramente uma apreensão dos seus tesouros acumulados. O produto do campo é algo diverso do proveniente do solo, pois o campo, se bem cultivado, guarda a fertilidade. Mas o produto da mina é parte da própria mina” (MARSHALL, 1996, p. 229).
} 
Aceita essa posição, os royalties passarão a ser classificados nas Leis Orçamentárias dos entes políticos como receita de capital, fruto da alienação de um bem público, e não mais como uma receita corrente patrimonial, decorrente da exploração de um bem público.

Qual a relevância disso? Uma vez classificados como receitas de capital, somente poderão ser aplicados em despesas de capital, ou seja, basicamente em investimentos e inversões financeiras, de acordo com o artigo 44 da Lei de Responsabilidade Fiscal. Desse modo, fica vedada a possibilidade, tal qual tem sido feito, de serem utilizados no custeio da máquina pública, aplicação contrária a uma lógica de uso sustentável dessas receitas.

Para tanto, iniciam-se nossos estudos discorrendo sobre o conteúdo jurídico do princípio da soberania dos Estados sobre seus recursos naturais. Este princípio, reconhecido pela ordem internacional, atribui às nações o poder de regular a forma como tais recursos serão explorados, com vistas a beneficiar sua população, além de lhes ser assegurado, permanentemente, o direito de nacionalização das jazidas, quando existam razões de utilidade pública, segurança ou interesse nacional que se revelem superiores a meros interesses particulares.

Ademais, tendo em vista que a soberania será exercida apenas sobre os recursos naturais que se encontrem nos estritos limites do seu território, será analisado também neste primeiro capítulo os limites do território brasileiro, com ênfase na sua porção marítima, que comporta maior controvérsia.

No capítulo 2 será analisado o regime de propriedade a que está sujeito o petróleo no direito brasileiro, sua caracterização como bem público, a discussão existente na doutrina e jurisprudência, e se consiste num bem público especial ou dominical. Serão vistos também conceitos técnicos essenciais à compreensão do tema, tais como a definição de petróleo, jazida, campo, bloco, entre outros.

O capítulo 3 tem um papel fundamental nesta tese. Nele se busca conhecer o objeto dos contratos petrolíferos, para que, assim, seja identificada a natureza das prestações a cargo de cada uma das partes envolvidas no contrato, dentre elas, os royalties. Nesta ocasião, defende-se a impossibilidade de se falar em uso do petróleo, e, com base nessa premissa, analisam-se as características de cada um dos modelos contratuais utilizados na indústria do petróleo: contrato de concessão, partilha da produção, de serviço, e, no Brasil, de cessão onerosa.

No capítulo 4, pretende-se demonstrar que as receitas pagas pelas empresas 
petrolíferas ao Estado brasileiro, em qualquer modelo contratual, correspondem a uma contraprestação pelo bem adquirido - no caso, o petróleo. No contrato de partilha da produção, essa tese será visualizada mais facilmente, uma vez que após receber sua parcela do óleo extraído, a União contratará uma empresa para vendê-lo; esta, por sua vez, firmará contrato de compra e venda com um comprador, por exemplo, uma refinaria, repassando ao ente central o preço recebido na operação. Já no contrato de concessão, a União opta por negociá-lo diretamente com a empresa contratada para sua extração, pelo fato de esta já possuir know-how em negociar esse recurso com aqueles interessados em adquiri-lo. O valor recebido pelo ente público, em vez de ser chamado apenas de preço, como ocorre no contrato de partilha - embora também seja um preço -, é denominado royalty, sobre o qual se discorrerá com mais profundidade.

Em seguida, será visto no capítulo 5 como é organizado no Estado brasileiro o planejamento da ação estatal, que se perfaz por meio da elaboração do Plano Plurianual (PPA), da Lei de Diretrizes Orçamentárias (LDO) e da Lei Orçamentária Anual (LOA). Com base no que já foi definido nos capítulos anteriores, defende-se que por serem uma receita recebida em contraprestação à alienação de um bem público, não em razão da sua exploração, os royalties representarão sempre uma conversão, em espécie, de um bem público, devendo ser registrados na LOA como uma receita de capital, e não mais como uma receita corrente, conforme dicção do parágrafo $2^{\circ}$ do artigo 11 da Lei $4.320 / 64$.

No capítulo 6 enfoca-se a partilha dos royalties no Estado brasileiro. Para tanto, inicia-se a análise pelo comando constitucional que impõe essa transferência de recursos entre os entes federativos brasileiros, para, em seguida, verificar, em detalhes, como a legislação ordinária operacionalizou essa repartição.

Contudo, não se deixa de, em um primeiro momento, expor os principais argumentos econômicos contra e a favor da descentralização das rendas petrolíferas, debatidos na doutrina nacional e internacional, verificando em que medida é eficiente que estas receitas permaneçam nos entes locais ou regionais, ou se devem ser concentradas no governo federal.

Por fim, no capítulo 7, será vista a consequência da alteração na classificação dos royalties na forma e limites para a sua utilização na Lei Orçamentária Anual, alteração esta que independeria da edição de Lei, porquanto se trata apenas de uma mudança de postura interpretativa. 


\section{CONCLUSÕES}

Não é exagero afirmar que o uso eficiente das receitas petrolíferas é condição sine qua non para que o Brasil caminhe definitivamente em direção ao desenvolvimento, entendida esta expressão não apenas sob a perspectiva de mero crescimento econômico, mas também de elevação nos padrões de qualidade de vida da população.

A realização de estudos que visem discutir a forma como são alocadas tais receitas é essencial para que a riqueza gerada com a produção do petróleo, na recémdescoberta região do pré-sal, não promova apenas mais um "surto" de crescimento no país. Se assim for, corre-se o risco de transformar essa benesse concedida pela natureza em apenas mais um ciclo econômico, que invariavelmente chegará ao fim, como historicamente exemplificam os ciclos da cana-de-açúcar, da borracha e do café, que declinaram levando consigo a oportunidade de promover um desenvolvimento nacional duradouro.

A revisão da natureza jurídica dos royalties lato sensu para fins de classificação na Lei Orçamentária dos entes federativos brasileiros, por meio do reconhecimento de que constituem receitas de capital e não receitas correntes, é um passo importante nesse sentido. Tal procedimento impõe um maior rigor à sua utilização, proibindo aplicá-los em despesas correntes, medida que tende a tornar mais eficiente o seu gasto.

Tal conclusão, contudo, só foi possível após um longo percurso argumentativo, no qual se realizou uma profunda revisão tanto da natureza jurídica atribuída aos contratos petrolíferos, como da receita pública arrecadada pelo Estado em razão destes.

Por se basear em novas concepções acerca de institutos já consagrados, esta tese foi construída seguindo um encadeamento lógico de ideias, de modo que a conclusão do capítulo precedente servia de premissa para a compreensão do capítulo seguinte. Em razão disso, a conclusão final encontra-se conectada àquelas formuladas desde o início do estudo, motivo pelo qual se optou por concluir este estudo por meio da retomada de todas elas, organizadas de maneira pontual, o que facilita a exposição do raciocínio:

Cap. 1 - O Direito Internacional assegura aos Estados Nacionais, por meio do 
princípio da soberania sobre os recursos naturais, o exercício de uma liberdade na escolha da melhor forma para explorar seus recursos. Não impõe a adoção de um regime de propriedade que deve ser seguido, nem algum tipo de modelo contratual a ser adotado. Podem optar por qualquer um dos caminhos possíveis, que se restringem basicamente a dois: (i) as jazidas pertencem ao proprietário da terra, conforme ainda se verifica nos Estados Unidos; ou (ii) pertencem ao Estado, sendo o seu proprietário o ente central ou o ente subnacional onde os recursos estão localizados, assegurando-se a possibilidade de nacionalização, expropriação ou requisição das áreas concedidas, quando existam razões de utilidade pública, segurança ou interesse nacional que se revelem como superiores a meros interesses particulares, seja de agentes internacionais ou nacionais.

Cap. 2 -A potencial alienação a que está sujeito o petróleo é a condição que o identifica como bem dominical, diferenciando-o dos bens de uso comum do povo e de uso especial. Estes podem sofrer avaliação econômica, porém se encontram sob o uso direto ou indireto da Administração, motivo por que não podem ser alienados sem que haja ato prévio de desafetação.

Mesmo passíveis de disposição, os bens dominicais não deixam de cumprir finalidades públicas, podendo o Estado regular o seu uso, ainda que realizado por particular, com vistas a atender aos objetivos de interesse coletivo, como faz o Estado brasileiro com relação ao petróleo, em que o ente público possui total liberdade para decidir quando, quais e com que periodicidade serão licitados blocos para exploração e eventual produção, além de ter à sua disposição uma série de mecanismos de controle tanto do nível de produção, como para sua comercialização.

Cap. 3 - Ao analisar as espécies de contratos de concessão para uso de bens públicos, verificou-se que esse tipo de concessão pode se apresentar sob duas modalidades: a de exploração ou a de simples uso do bem público. Na primeira, confere-se ao contratado, além do uso, um poder de gestão dominial que o autoriza, inclusive, a dispor de parcelas do bem. Já na segunda, como o próprio nome sugere, atribui-se apenas a possibilidade de uso do bem público.

Com relação ao petróleo, a doutrina costuma enquadrar o objeto dos contratos de exploração e produção desse recurso, seja em que modelo for (contrato de concessão, partilha da produção ou contrato de serviço), naquela primeira espécie, isto é, entre os 
contratos de concessão para exploração de bem público.

Contudo, não é possível atribuir aos contratos petrolíferos natureza de contrato para exploração de bem público, tendo em vista que por meio destes se autoriza tão só o uso com disposição parcial da coisa, sem alteração da substância do bem principal. Por meio dos contratos petrolíferos, o petróleo armazenado nas jazidas tem sua propriedade gradualmente transferida à companhia petrolífera. Desse modo, a retirada de cada barril leva à exaustão da jazida, motivo por que é absolutamente impossível falar em uso com poderes de disponibilidade, já que, ao final, haverá o esgotamento do bem principal. Assim, o que de fato ocorre é a alienação de um bem ao particular, não uma concessão para uso.

Cap. 4 - Depois de extraído o petróleo, poderá o Estado auferir receitas públicas com a sua comercialização, seja por meio de contrato de compra e venda, em instrumento apartado daquele firmado com a empresa que explorou e produziu o recurso (contrato de partilha e de serviço), seja diretamente com esta, por meio de acordo de compra e venda inserto no contrato de E\&P (contrato de concessão). Nas duas hipóteses, a receita pública arrecadada terá natureza de preço público, devido em contraprestação à alienação de um bem público.

Nesse contexto, concluiu-se que os royalties lato sensu pagos pelas empresas petrolíferas consistem no preço devido ao Estado em contraprestação à alienação de um bem público, sempre que o negócio jurídico de compra e venda de petróleo estiver previsto, concomitantemente, no contrato de exploração e produção.

Cap. 5 - Atualmente, a União e os demais entes da federação registram toda a receita obtida com a venda do petróleo, em suas respectivas Leis Orçamentárias, como receita corrente patrimonial, devida em razão do usufruto de um bem público.

Contudo, o Manual de Contabilidade Aplicada ao Setor Público, que serve de guia para a elaboração do Orçamento, define receitas patrimoniais como sendo o “ingresso proveniente da fruição do patrimônio, pela exploração de bens imobiliários ou mobiliários, e da participação societária" (2009, p. 24, grifos nossos).

Assim, ao classificar os royalties lato sensu como receitas correntes em suas Leis Orçamentárias, os entes políticos conferem a essas receitas uma natureza que não se coaduna com a melhor técnica jurídica, já que não decorrem da fruição ou usufruto de um bem público, mas sim de sua alienação. 
Portanto, faz-se necessário que as Administrações Públicas federais, estaduais e municipais revejam sua interpretação acerca da natureza jurídica dessas receitas, passando a enquadrá-las em suas leis orçamentárias, em obediência à Lei n. 4.320/64, como receitas de capital. Tal iniciativa deve partir, necessariamente, da Administração Pública federal, que uma vez registrando esses valores como receitas de capital, torna obrigatório, por força do disposto no artigo $11, \S 2^{\circ}$, da Lei 4.320/64, em conjunto com o artigo 44 da LRF, que Estados e Municípios procedam da mesma forma, independentemente da edição de qualquer Lei, porquanto se trata apenas de uma mudança de postura interpretativa.

Cap. 6 - Após ingressarem nos cofres do Tesouro Nacional, as receitas públicas pagas a título de royalties lato sensu pelas companhias petrolíferas deverão ser distribuídas aos beneficiários eleitos pela legislação, em obediência ao artigo 20, parágrafo $1^{\circ}$, da Constituição Federal. Uma parte permanecerá com a União, e outra será destinada a Estados e Municípios, notadamente aqueles em cujo território sejam desenvolvidas atividades extrativas.

Como visto, a repartição das receitas no Estado brasileiro suscita uma série de controvérsias econômicas e políticas, as quais, conforme demonstrado, se irradiam também no campo jurídico.

Foram respondidos questionamentos importantes, tais como: quem deverá efetuar o pagamento dos royalties lato sensu? Quem são exatamente os beneficiários dessas receitas, enunciados no artigo 20, parágrafo $1^{\circ}$, da CF? Que espécies de receitas devem ser entregues aos entes beneficiários? Toda e qualquer receita não tributária arrecadada de companhias petrolíferas? O que a Constituição quis dizer com participação no resultado ou compensação financeira pela exploração? Qual a medida da participação de cada ente?

Por fim, verificou-se que o quantum devido aos entes produtores deve ser obtido à luz do princípio da razoabilidade. Tal princípio deve servir, ao Legislativo, como parâmetro para o estabelecimento das alíquotas das receitas petrolíferas a serem transferidas, e ao Judiciário, para a sua revisão, caso as alíquotas estabelecidas pela legislação não sejam razoáveis. Isso tanto pode se verificar seja porque tais receitas não compensam devidamente os entes subnacionais, seja por destinarem a estes um montante muito superior ao adequado, em detrimento de toda a federação, uma vez que esses recursos são provenientes de um bem que pertence à União. 
Cap. 7 - A alteração na classificação das rendas petrolíferas, conforme sugerido no presente estudo, de receitas correntes para receitas de capital, altera o seu regime de aplicação, limitando o seu gasto a cobrir despesas de capital.

Essa mudança teria início, necessariamente, na classificação dos royalties lato sensu da Lei Orçamentária Anual da União. Estes passariam a ser registrados como receitas de capital, assim como deverá ocorrer com a receita obtida com a venda do petróleo in natura, obtido pela União por meio dos contratos de partilha da produção.

Uma vez registrados na LOA do ente central como receitas de capital, estariam adstritos a financiar despesas de capital, que, segundo o artigo 12 da Lei 4.320/64, constituem investimentos, inversões financeiras e transferências de capital.

Essa nova classificação da receita promovida pela União teria impacto direto também na forma como devem ser registradas as compensações financeiras repassadas aos Estados e Municípios. Como o artigo 44 da LRF veda a aplicação das receitas de capital para o financiamento da despesa corrente, elas não poderiam ser transferidas aos Estados e Municípios a título de transferência corrente, que é uma forma de despesa corrente, mas tão só como transferência de capital. Assim, os beneficiários dos recursos repassados também estariam limitados a utilizá-los em investimentos ou inversões financeiras, conforme determina o parágrafo $6^{\circ}$ do artigo 12 da Lei 4.320/64. 


\section{REFERÊNCIAS}

ADAMSON, R.G. The Interest of the Developer. In: Resource Use Resolving the Conflicts: present and proposed policies and legal mechanisms for resource use in New Zealand. FISHER, D. E. (org.). Wellington: Energy and Natural Resources Law Association of New Zealand Inc, 1986.

AFONSO, José Roberto Rodrigues; GOBETTI, Sérgio Wulff. Rendas do Petróleo no Brasil: alguns aspectos fiscais e federativos. Revista do BNDES. Rio de Janeiro, V. 15, n. 30, p. 231-269, dez. 2008.

AHMAD, Ehtisham; MOTTU, Eric. Oil Revenue Assignments: Country Experiences and Issues. In: Fiscal Policy Formulation and Implementation in Oil-Producing Countries. J. M. Davis, R. Ossowski, and A. Fedelino. (Org.). Washington, D.C.: International Monetary Fund, 2003.

ALVES, Landulpho. O Problema Brasileiro do Petróleo. Rio de Janeiro: A Noite, 1954.

AMBROSE, Rona. Government Revenues from Natural Resources: The Canadian Experience. Palestra proferida na Associação Comercial de Santos em 16 de julho de 2007. Disponível em: <www.forumfed.org/pubs/Ambrose_160707.doc>. Acesso em 30 de outubro de 2009.

ANP. AGÊNCIA NACIONAL DO PETRÓlEO, GÁS NATURAL E BIOCOMBUSTÍVEIS. Consolidação das Participações Governamentais e de Terceiros. 2011. Disponível em: < http://www.anp.gov.br/?id=518>. Acesso em: 12 de fevereiro de 2012.

ARAGÃO, Alexandre Santos de. O Contrato de Concessão de Exploração de Petróleo e Gás. In: Revista Eletrônica de Direito Administrativo Econômico. N. 5. Fev./mar./abr. de 2006, Salvador, IDPB. 
ARAÚJO, Edmir Netto de. Curso de Direito Administrativo. 5. ed. São Paulo: Saraiva, 2010.

AQUINO, Ducinelli Régis Botelho de; MOREIRA, Jordão Ribeiro; NIYAMA, Jorge Katsumi. Estudo Comparativo dos Critérios de Mensuração das Reservas Provadas, segundo SPE/WPC e SEC: o caso da PETROBRAS. In: Revista de Contabilidade do Mestrado em Ciências Contábeis da UERJ, Rio de Janeiro, v. 11, n. 2, p. 1, jul./dez. 2006.

ATAliBA, Geraldo. Apontamentos de Ciência das Finanças, Direito Financeiro e Tributário. São Paulo: Revista dos Tribunais, 1969.

BAHL, Roy. Revenue Sharing in Petroleum States. In: World Bank Oil, Gas, Mining and Chemicals Department. World Bank/UNDP Energy Sector Management Assistance Programme - ESMAP (orgs.). Petroleum Revenue Management Workshop, 2004.

BALEEIRO, Aliomar. Uma Introdução à Ciência das Finanças. 14. ed. Rio de Janeiro: Forense, 1986.

BANCO MUNDIAL. Comparative study on the distribution of oil rents in Bolivia, Colombia, Ecuador and Peru. ESMAP: 2005.

BARBOSA, Alfredo Ruy. A Natureza Jurídica da Concessão para Exploração de Petróleo e Gás Natural. In: Temas de Direito do Petróleo e do Gás Natural II. PIRES, Paulo Valois (org.). Rio de Janeiro: Lumen Juris, 2005.

BARBOSA, Décio. Guia dos royalties do petróleo e do gás natural. Rio de Janeiro: ANP, 2001.

BARBOSA, Décio. Tributação do Petróleo no Brasil e em outras jurisdições. Rio de Janeiro: Livre Expressão, 2011.

BASTOS, Celso Ribeiro. Curso de Direito Financeiro e de Direito Tributário. 2. ed. São Paulo: Saraiva, 1992. 
BERCOVICI, Gilberto. Direito Econômico do Petróleo e dos Recursos Minerais. São Paulo: Quartier Latin, 2011.

BERCOVICI, Gilberto. Constituição e Superação das Desigualdades Regionais. In: GRAU, Eros Roberto; GUERRA FILHO, Willis Santiago (orgs.). Direito Constitucional: estudos em homenagem a Paulo Bonavides. São Paulo: Malheiros, 2003.

BERCOVICI, Gilberto. Desigualdades Regionais, Estado e Constituição. São Paulo: Max Limonad, 2003.

BERCOVICI, Gilberto. Desequilibrios Regionais: Uma análise jurídico-institucional. 2000. 350 f. Tese (Doutorado em Direito do Estado) - Universidade de São Paulo, São Paulo, 2000.

BEY, Essad. A Luta pelo Petróleo. Tradução de Charley W. Frankie. São Paulo: Companhia Editora Nacional, 1953.

BONAVIDES, Paulo. Curso de Direito Constitucional. 18. ed. São Paulo: Malheiros, 2006.

BRASIL. Secretaria do Tesouro Nacional. Manual de contabilidade aplicada ao setor público: aplicado à União, aos Estados, ao Distrito Federal e aos Municípios: procedimentos contábeis orçamentários / Ministério da Fazenda, Secretaria do Tesouro Nacional, Ministério do Planejamento, Orçamento e Gestão, Secretaria de Orçamento Federal. - 2. ed. - Brasília : Secretaria do Tesouro Nacional, Coordenação-Geral de Contabilidade, 2009.

BREGMAN, Daniel. Um Estudo sobre a Aplicação dos Royalties Petrolíferos no Brasil. Brasília: ESAF, 2007

BROSIO, GIORGIO. Oil Revenue and Fiscal Federalism. In: Fiscal Policy Formulation and Implementation in Oil-Producing Countries. J.M. Davis, R. Ossowski 
and A. Fedelino (org.). Washington, D.C.: International Monetary Fund, 2003.

BROSIO, Giorgio. The assignmente of Revenue from Natural Resources. In: AHMAD, Ehtisham, BROSIO, Giorgio (org.). Handbook of Fiscal Federalism. Massachusetts: Edward Elgar Publishing, 2006.

CAIRNS, Robert. D. Natural Resources and Canadian Federalism: Decentralization, Recurring Conflict, and Resolution. Disponível em: $<$ http://publius.oxfordjournals.org/cgi/content/abstract/22/1/55>. Acesso em: 12 de outubro de 2009.

CAMPOS JR, José Julio F. Valoração econômica de danos ambientais: o caso dos derrames de petróleo em São Sebastião. Tese de doutorado. Unicamp: Campinas, 2003.

CARRAZZA, Roque Antônio. Natureza Jurídica da Compensação Financeira pela Exploração de Recursos Minerais. Sua Manifesta Inconstitucionalidade. Justitia, São Paulo; 57(171) jul/set. $1995 . \quad$ Disponível em: $<$ http://www.justitia.com.br/revistas/xw21yw.pdf $>$. Acesso em: 17 de setembro de 2009.

CARVALHO, A. C. Vinculação de receitas públicas. São Paulo: Quartier Latin, 2010.

CARVAlHO, Aurora Tomazini. Curso de Teoria Geral do Direito: o constructivismo lógico-semântico. São Paulo: Noeses, 2009.

CARVAlHO, Flávia Caheté Lopes. Aspectos Éticos da Exploração do Petróleo: Os Royalties e a Questão Intergeracional. 2008. 84 f. Dissertação (Mestrado em Ciências em Planejamento Energético) - Universidade Federal do Rio de Janeiro, Rio de Janeiro, 2008.

CARVALHO, Paulo de Barros. Direito Tributário Linguagem e Método. 3. ed. São Paulo: Noeses, 2009.

CARVALHO, Paulo de Barros. Direito Tributário: fundamentos jurídicos da 
incidência. 8. ed. São Paulo: Saraiva 2010.

CASELLA, Paulo Borba. Direito Internacional dos Espaços. São Paulo: Atlas, 2009.

CAVALCANTE, Amanda Barcellos. Direitos do Proprietário de Terra na Exploração e Produção do Petróleo e Gás. Artigo apresentado no $2^{\circ}$ Congresso Brasileiro de P\&D em Petróleo e Gás. Rio de Janeiro, 15 a 18 de junho de 2003.

CHIRCOP, Aldo; MARCHAND, Bruce. Oceans Act: Uncharted Seas For Offshore Development in Atlantic Canada? Nova Scotia: The Dalhousie Law Journal, 2001.

CIRM, COMISSÃO INTERMINISTERIAL PARA RECURSOS DO MAR. Disponível em: <http://www.mar.mil.br/secirm/leplac.htm>. Acesso em: 29 de agosto de 2010.

CLÈVE, Clèmerson Merlim; MARTINS, Alessandra Ferreira. Princípios Constitucionais da Atividade Econômica Petrolífera e Lei n. 9.478 de 1997. In: Revista de Direito Administrativo e Constitucional. Belo Horizonte: Fórum, ano 4, n. 18, out/dez.2004.

COMPARATO, Fábio Konder. A Afirmação Histórica dos Direitos Humanos. São Paulo: Saraiva, 1999.

CONTI, José Maurício. Federalismo Fiscal e Fundos de Participação. São Paulo: Editora Juarez de Oliveira, 2001.

COSTA, Armando João Dalla. ORTIZ NETO, João Benedito. A Petrobrás e a Exploração de Petróleo Offshore no Brasil: um approach evolucionário. Revista Brasileira de Economia. Disponível em: $<$ http://www.scielo.br/pdf/rbe/v61n1/a06v61n1.pdf $>$. Acesso em: 26 de agosto do 2010.

CREEL, Jérôme; POILON, Gwenaëlle. Is public capital productive in Europe? 2006. Disponível em: <http://ideas.repec.org/p/fce/doctra/0610.html $>$. Acesso em: 24 de março de 2013. 
CRETElla JÚNIOR, José. Dos Bens Públicos na Constituição de 1988. São Paulo: Revista dos Tribunais, 1990. V. 79, n. 653.

CRETELlA JÚNIOR, José. Comentários à Constituição de 1988. Vol. III, Rio de Janeiro: Forense, 1991.

DAINTITH, Terence. The legal character of petroleum licences: a comparative study. Dundee: University of Dundee, 1981.

DALEFFE, Adriano. Ilegalidade da Compensação Financeira pela Exploração de Recursos Minerais. In: Revista Dialética de Direito Tributário, São Paulo, jun. 1998, v. 33.

DANTAS, Fernando. Doença Holandesa Já é um Risco. O Estado de São Paulo. São Paulo, SP, 14 fev. 2006. Disponível em: $<$ http://www.fazenda.gov.br/resenhaeletronica/MostraMateria.asp?page $=\& \operatorname{cod}=2660$ 80>. Acesso em: 27 de outubro de 2008.

DAVIS, J.M.; FEDELINO, A.; OSSOWSKI, R. Fiscal Policy Formulation and Implementation in Oil - Producing Countries. Washington D.C.: International Monetary Fund: 2003.

DE PLÁCIDO E SILVA. Vocabulário Jurídico. 2. ed. São Paulo/Rio: Forense: 1967, v. II.

DE PLÁCIDO E SILVA. Vocabulário Jurídico. 2. ed. São Paulo/Rio: Forense: 1967, v. IV.

DEODATO, Alberto. Manual de Ciência das Finanças. 21. ed. São Paulo: Saraiva, 1987.

DI PIETRO, Maria Sylvia Zanella. Direito Administrativo. 24. ed. São Paulo: Atlas, 2011. 
DIAS, José Luciano M., QUAGLINO, Maria Ana. A questão do petróleo no Brasil, uma história da Petrobras. Rio de Janeiro: Fundação Getúlio Vargas - Petrobras, 1993.

DIEZ, Manuel Maria. Derecho Administrativo. Buenos Aires: Libreros, 1969.

DINIZ, Maria Helena. Tratado Teórico e Prático dos Contratos. Volume 5. 6. ed. São Paulo: Saraiva, 2006.

EPE. EMPRESA DE PESQUISA ENERGÉTICA (BRASIL). Balanço Energético Nacional 2011: ano base 2010. Rio de Janeiro: EPE, 2011. Disponível em: < https://ben.epe.gov.br/downloads/Relatorio_Final_BEN_2011.pdf>. Acesso em: 12 de fevereiro de 2012.

ECS, ENERGY CHARTER SECRETARIAT. Putting a price on Energy: international pricing mechanisms for oil and gas. Brussels: Energy Charter Secretariat, 2007.

EXAME. Veja como as cidades brasileiras investem os royalties do petróleo. 2007. Disponível em: <http://exame.abril.com.br/revista-exame/edicoes/0892/noticias/vejacomo-as-cidades-brasileiras-investem-os-royalties-do-petroleo-m0128066>. Acesso em: 25 de fevereiro de 2011.

FARE, R. et al. Production frontiers. Cambridge University Press, 1994.

FERNANDES, Andressa G. Torquato. Uma análise acerca da classificação das receitas petrolíferas na Lei Orçamentária. In: Orçamento Público e Direito Financeiro. CONTI, José Mauricio; SCAFF, Fernando Facury. (org.). São Paulo: Revista dos Tribunais, 2011, p. 433-451.

FERNANDES, Andressa G. Torquato. Royalties internacionais do pré-sal: por que ninguém está falando neles? In: Revista Fórum de Direito Financeiro e Econômico. OLIVEIRA, Regis Fernandes de; SCAFF, Fernando Facury (orgs.). São Paulo: Fórum, 2012.

FERREIRA FILHO, Manoel Gonçalves. Comentários à Constituição brasileira de 
1988. São Paulo: Saraiva, 1992. V. 1.

FERREIRA, Renata Marques. FIORILlO, Celso Antonio Pacheco. Curso de Direito da Energia: tutela jurídica da água, do petróleo, do biocombustível, dos combustíveis nucleares e do vento. 2. ed. São Paulo: Saraiva, 2010.

FIESCNET. FEDERAÇÃO DAS INDÚSTRIAS DO ESTADO DE SANTA CATARINA. Disponível em: $<$ http://www2.fiescnet.com.br/web/pt/site/infra/info/historia-do-petroleo-no-brasil $>$. Acesso em: 14 de abril de 2009.

FIORATI, Jane Jete. A disciplina jurídica dos espaços marítimos na Convenção das Nações Unidas sobre direito do mar de 1982 e na jurisprudência internacional. Rio de Janeiro: Renovar, 1999.

FISCHMAN, Robert L. Cooperative Federalism and Natural Resources Law. Disponível em: $<$ http://www1.law.nyu.edu/journals/envtllaw/issues/vol14/1/v14_n1_fischman.pdf $>$. Acesso em: 12 de outubro de 2009.

FONROUGE, Giuliani. Derecho Financiero. 2. ed. Buenos Aires: Depalma, 1970. v.1.

FONSECA, Maria M. Metodologia para previsão de longo prazo de preços do petróleo. ANP, 2005.

FRANCARIO, Fabio. Le Miniere, le Cave e le Torbiere. In: Trattato di Diritto Amministrativo. CASSESE, S. (org.). Tomo II. Milano: Giuffrè Editore, 2003.

FREIRE, William. Código de Mineração Anotado. 4. ed. Belo Horizonte, Mandamentos, 2009.

FREITAS, Miguel Lebre de. 2004. Disponível em: $<$ http://sweet.ua.pt/ afreitas/opiniao/semanec36.pdf>. Acesso em: 25 de março de 2013. 
FREITAS, Paulo Springer de. Rendas do Petróleo: questão federativa e instituição de fundo soberano. Artigo apresentado no IV Fórum Senado Debate Brasil - Nova fronteira do petróleo: os desafios do pré-sal. Brasília, 3 e 4 de dezembro de 2008.

GASPAR, Malu; TEIXEIRA JÚNIOR, Sérgio. A Riqueza do Fundo do Mar. EXAME, n. 16, p. 24, ago. 2008. Edição 925.

GOBETTI, Sérgio Wulff. Política fiscal e pré-sal: Como gerir as rendas do petróleo e sustentar o equilíbrio macro-fiscal do Brasil. Brasília: ESAF, 2009.

GOMES, Orlando. Direitos Reais. Rio de Janeiro: Forense, 1983.

GONZAGA, Luiz. Disponível em: $<$ http://www.gazetadooeste.com.br/16_abril_08/luiz.htm>. Acesso em: 27 de outubro de 2008.

GROTIUS, Hugo. The Freedom of the Seas or the right which belongs to the dutch to take part in the east indian trade. New York: Oxford University Press, 1916.

GRAY, Dale F. Evaluation of taxes and revenues from the energy sector in the Baltics, Russia, and other former Soviet Union countries. IMF Working Paper, 1998.

GUTMAN, José. Tributação e outras obrigações na indústria do petróleo. Rio de Janeiro: Freitas Bastos, 2007.

HANNESSON, Rognvaldur. Petroleum Economics: issues and strategies of Oil and Natural Gas Production. Westport: Quorum Books, 1998.

HARADA, Kiyoshi. Direito Financeiro e Tributário. 18. ed. São Paulo: Atlas, 2009.

HARG, Allien Mac; BARTON, Barry; BRADBROOK, Adrian; GODDEN, Lee. Property and the Law in Energy and Natural Resources. New York: Oxford University Press, 2010. 
IEA. International Energy Agency. Key World Energy Statistics 2011. Disponível em: $<$ http://www.iea.org/textbase/nppdf/free/2011/key_world_energy_stats.pdf $>$. Acesso em: 12 de fevereiro de 2012.

INGROSSO, Gustavo. Diritto Finanziario. Napoli: Casa Editrice Dott Eugenio Jovene, 1954.

INSTITUTO LATINOAMERICANO Y DEL CARIBE DE PLANIFICACIÓN ECONÓMICA Y SOCIAL - ILPES. Panorama de la gestión pública. Santiago de Chile: Naciones Unidas, ILPES, 2004, p. 140.

JENNINGS, Anthony. Oil and Gas Exploration Contracts. London: Sweet \& Maxwell, 2002.

JOHNSTON, Daniel. International Petroleum Fiscal Systems and Production Sharing Contracts. Tulsa: Penn Well Publishing, 1994.

KAHN, Mauro. O efeito multiplicador da indústria do petróleo. Disponível em: < http://www.artigonal.com/noticias-e-sociedade-artigos/o-efeito-multiplicador-daindustria-do-petroleo-917374.html>. Acesso em: 12 de fevereiro de 2012.

KARL, Terry Lynn. Entendendo a Maldição dos Recursos Naturais. In: TSALIK, S., SCHIFFRIN, A. (orgs.). Reportando o Petróleo: Um Guia Jornalístico sobre Energia e Desenvolvimento. New York: Open Society Institute, 2005.

KARL, Terry Lynn. The Paradox of Plenty: oil booms and petro-states. Berkeley: University of California Press, 1997.

KOHLER, Marcos; MENDES, Marcos. Os Estados e Municípios devem receber royalties de petróleo? Disponível em: <http://www.brasil-economiagoverno.org.br/2011/06/06/os-estados-e-municipios-devem-receber-royalties-depetroleo/>. Acesso em: 24 de março de 2012.

LARA, Marilda Lopez Ginez de (2004). Diferenças conceituais sobre termos e 
definições e implicações na organização da linguagem documentária. Rev. Ci. Inf., Brasília, v. 33, n. 2, p. 91-96, maio/ago. 2004. Disponível em: $<$ http://www.scielo.br/pdf/ci/v33n2/a09v33n2.pdfScielo $>$. Acesso em: 8 de fevereiro de 2012.

LEAL, José Agostinho A., SERRA, Rodrigo V. Uma investigação sobre os critérios de repartição e aplicação dos royalties petrolíferos. In: PIQUET, Rosélia (org.). Petróleo, Royalties e Região. Rio de Janeiro: Editora Garamond, 2003.

LEAL, José Agostinho A., SERRA, Rodrigo V. Federalismo fiscal e repartição dos royalties petroliferos no Brasil. Cadernos IPPUR, Ano XVII, n. 1, 2003.

LODGE, Michael. The International Seabed Authority and Article 82 of the UN Convention on the Law of the Sea. Koninklijke Brill NV: The International Journal of Marine and Coastal Law, Vol. 21, N. 3, 2006.

LRF. Lei de Responsabilidade Fiscal. Disponível em: <www.lrf.com.br>. Acesso em: 05 de abril de 2013.

MACHADO JR, J. Teixeira; REIS, Heraldo da Costa. A Lei 4.320 Comentada. 32. ed. Rio de Janeiro: IBAM, 2008.

MARQUES, José Augusto Veiga da Costa; MÜNCH, Marcelo Guimarães; MUNIZ, Natiara Penalva; RIBEIRO, Rogério Afonso. Reservas de Petróleo e Gás: os investidores possuem informação suficiente para suas análises? In: $4^{\circ}$ PDPETRO. Campinas-SP, 21-24 de outubro de 2007.

MARQUES NETO, Floriano Peixoto de Azevedo. Bens Públicos: função social e exploração econômica. Belo Horizonte: Forum, 2009.

MARQUES NETO, Floriano de Azevedo. Cessão onerosa dos direitos de E\&P em áreas do Pré-sal: questões jurídicas sobre a competição no Pré-sal. In: $1^{\circ}$ Seminário Brasileiro do Pré-sal. Auditório do MME, Brasília, ago. 2010. 
MARSHAL, Alfred. Princípios de Economia: tratado introdutório. Tradutores Rômulo Almeida e Ottolmy Strauch. São Paulo: Nova Cultura, 1996.

MATOSO, Rafael Silva. Leilões de Blocos Exploratórios de Petróleo e Gás no Brasil: estudo do papel da Petrobras. Dissertação. Mestrado Profissionalizante em Economia. Faculdade de Economia e Finanças IBMEC. Orientador: Marcelo Ferreira da Motta Rezende. Rio de Janeiro: 23 de dezembro de 2009.

MAZZUOLI, Valerio de Oliveira. Curso de Direito Internacional Público. 4. ed. São Paulo: Revista dos Tribunais, 2010.

McLURE JR, CHARLES E. The Assignment of Oil Tax Revenue. In: Fiscal Policy Formulation and Implementation in Oil-Producing Countries. J.M. Davis, R. Ossowski, and A. Fedelino (org.). Washington, D.C.: International Monetary Fund, 2003.

MEIRELLES, Hely Lopes. Direito Administrativo Brasileiro. 34. ed. São Paulo: Malheiros, 2007.

MELlo, Celso Antônio Bandeira de. Curso de Direito Administrativo. 35. ed. São Paulo: Malheiros, 2007.

MENDES, Marcos José.Federalismo Fiscal. In: ARVATE, Paulo Roberto; BIDERMAN, Ciro (Org.). Economia do Setor Público. 1. ed. Rio de Janeiro: Campus/Elsevier, 2004, v. 1.

MENEZELlo, Maria D’Assunção Costa. Comentários à Lei do Petróleo. São Paulo: Atlas, 2009.

MINATEL, José Antonio. Conteúdo do Conceito de Receita e Regime Jurídico para sua Tributação. São Paulo: MP Editora, 2005.

MEYERS, Charles J. WILLIAMS, Howard R. Oil and Gas Law. Lexis Nexis, 2008.

MONIZ, Ana Raquel Gonçalvez. O Domínio Público - O Critério e o Regime Jurídico 
da Dominialidade. Lisboa: Almedina, 2006.

MORAES, Alexandre de. Constituição do Brasil interpretada e legislação constitucional. 4. ed. São Paulo: Atlas, 2004, p. 658.

MORAES, Alexandre de. Regime Jurídico da Concessão para Exploração de Petróleo e Gás Natural. In: Revista de Direito Constitucional e Internacional, n. 36. Ano 9. São Paulo: Revista dos Tribunais, Julho-setembro de 2001.

NASCIMENTO, A. Theodoro. Preços, Taxas e Parafiscalidade. Rio de Janeiro: Forense, 1977.

NASCIMENTO, Juliana Alves do. Perspectivas de Investimentos para E\&P. Mudanças na Regulação. Impactos Econômicos na Alteração das Regras de Concessão. Painel apresentado no IV Seminário de Petróleo e Gás no Brasil. 14 de abril de 2008.

NEW YORK TIMES. 1901. Disponível em: < http://query.nytimes.com/mem/archivefree/pdf?res=F30612F7355C12738DDDAD0A94DC405B818CF1D3\%E2\%80\%8F>. Acesso em: 12 de janeiro de 2012.

NUSDEO, Fábio. Desenvolvimento econômico - Um retrospecto e algumas perspectivas. In: SALOMÃO FILHO, Calixto (org.). Regulação e Desenvolvimento. São Paulo: Malheiros, 2002.

OMOROGBE, Yinka; ONIEMOLA, Peter. Property Rights in Oil and Gas under Domanial Regimes. In: Property and the Law in Energy and Natural Resources. MAC HARG, Allien; BARTON, Barry; BRADBROOK, Adrian; GODDEN, Lee. (orgs.). New York: Oxford University Press, 2010.

OLIVEIRA, Regis Fernandes de. Curso de Direito Financeiro. 2. ed. São Paulo: Revista dos Tribunais, 2008.

OLIVEIRA, Regis Fernandes de Oliveira. Prefácio. In: Orçamentos Públicos e Direito Financeiro. CONTI, José Mauricio; SCAFF, Fernando Facury (orgs.). São Paulo: 
Revista dos Tribunais, 2011.

ORTEGÓN, Edgar; PACHECO, Juan Francisco. Los sistemas nacionales de inversión pública em Centroamérica: marco teórico $\mathrm{y}$ análisis comparativo multivariado. Manuales, n. 34. Santiago de Chile: Naciones Unidas, ILPES/CEPAL, 2004, p. 40.

PEREIRA, Caio Mário da Silva. Instituições de Direito Civil: Direitos Reais, v. 4. 19. ed. Rio de Janeiro: Forense, 2006.

PEROGORDO, Juan Bayona de; ROCH, Maria Teresa Soler. Derecho Financiero. Alicante: Compas, 1987.

PETROBRAS, 2012, Disponível em: $<$ http://www.petrobras.com.br/minisite/presal/pt/uma-nova-fronteira/>. Acesso em: $8 \mathrm{de}$ maio de 2012.

PETROBRAS, 2010, Disponível em: $<$ http://www.investidorpetrobras.com.br/data/files/8A78D68433B26FD50133B281E87 F1039/Prospecto\%20Definitivo\%20port.pdf>. Acesso em: 24 de março de 2013.

PIMENTEL JÚNIOR. Temos Petróleo! São Paulo: [s.n.]. 1956.

PNUD. Programa das Nações Unidas para o Desenvolvimento Humano. Disponível em: $<$ http://www.pnud.org.br/atlas/ranking/IDH\%2091\%2000\%20Ranking\%20decrescente\%20(pelos\%20dados\%20de\%202000).htm>. Acesso em: 18 de outubro de 2008.

PONTES DE MIRANDA. Tratado de Direito Privado. Rio de Janeiro: Borsoi, 1954, Tomo II.

PONTES DE MIRANDA. Tratado de Direito Privado. 3. ed. Rio de Janeiro: Borsoi, 1972, Tomo XXII. 
PONTES DE MIRANDA. Tratado de Direito Privado. 3. ed. Rio de Janeiro: Borsoi, 1972, Tomo XXXVIII.

PONTES DE MIRANDA. Tratado de Direito Privado. 3. ed. Rio de Janeiro: Borsoi, 1972, Tomo XXXIX.

PONTES DE MIRANDA. Tratado de Direito Privado. 3. ed. Rio de Janeiro: Borsoi, 1972, Tomo XLIV.

PONTES DE MIRANDA. Tratado de Direito Privado. 3. ed. Rio de Janeiro: Borsoi, 1972, Tomo XLVII.

POSTALI, Fernando. Renda mineral, divisão de riscos e beneficios governamentais na exploração de petróleo no Brasil. Rio de Janeiro: BNDES, 2002.

REDGWELL, Catherine. Property Law Sources and Analogies in International Law. In: Property and the Law in Energy and Natural Resources. MAC HARG, Allien; BARTON, Barry; BRADBROOK, Adrian; GODDEN, Lee. (orgs.). New York: Oxford University Press, 2010.

REZENDE, Fernando. Federalismo Fiscal no Brasil. Revista de Economia Política, v. 15, n. 3, 1995.

RIBEIRO, Carlos Luiz. Direito Minerário Escrito e Aplicado. Belo Horizonte, Del Rey, 2006.

RIBEIRO, Marilda Rosado de Sá. Contratação Petrolífera em E \& P: Regime de Partilha de Produção. Disponível em:

$<$ http://www.senado.gov.br/sf/comissoes/ci/ap/AP20091005_SENADO_Regime_de_Pa rtilha_04_10_2009_MRO_v4Marilda.pdf $>$. Acesso em: 27 de fevereiro de 2011.

RIBEIRO, Marilda Rosado de Sá. Direito do Petróleo: as joint ventures na indústria do petróleo. 2. ed. Rio de Janeiro: Renovar, 2003. 
RICARDO, David. Princípios de Economia Política e Tributação. Tradução de Paulo Henrique Ribeiro Sandroni. São Paulo: Nova Cultura, 1996.

RISTER, Carla Abrantkoski. Direito ao Desenvolvimento: antecedentes, significados e conseqüências. Rio de Janeiro: Renovar, 2007.

ROSA JUNIOR, Luiz Emygdio F. da. Manual de Direito Financeiro e Direito Tributário. 2. ed. Rio de Janeiro: Freitas Bastos, 1979.

ROYAL DUTCH/SHELL GROUP OF COMPANIES. The Petroleum Handbook. 6. ed. Amsterdam: Elsevier, 1983.

RUBINSTEIN, Flávio. Orçamentos Públicos: a Lei 4.320/1964 comentada/ coordenador José Maurício Conti. São Paulo: Editora Revista dos Tribunais, 2008.

SALVATTI, Ideli. Disponível em: $<$ http://www.ideli.com.br/planejamento/index.php/conteudos/view/1183>. Acesso em: 30 de outubro de 2008.

SANTOS, Sérgio Honorato dos. Royalties do Petróleo: Legislação Atual Apresenta Deficiências quanto à Aplicação. Petróleo, Royalties e Região. Boletim do Mestrado em Planejamento Regional e Gestão de Cidades da Universidade Cândido Mendes, Rio de Janeiro: Ano II, n. 6, dez./2004.

SCAFF, Fernando Facury. Compensação Financeira pela Exploração de Recursos Minerais (CFEM): natureza jurídica, competência normativa e prescrição. In: Revista de Direito do Estado. Rio de Janeiro: Renovar, jul./set. 2006, v. 3.

SCAFF, Fernando Facury. Aspectos Controvertidos sobre a CFEM - Compensação Financeira pela Exploração de Recursos Minerais (Royalties de Mineração). In: SCAFF, Fernando Facury; ATHIAS, Jorge Alex (org.). Direito Tributário e Econômico Aplicado ao Meio Ambiente e à Mineração. São Paulo: Quartier Latin, 2009.

SCHANT Jr., Radford. Purpose and effects of a royalty on a public land materials. 
Resources Policy, vol. 20, n. 1, pp. 35-48, 1994.

SCHECHTMAN, Rafael et al. Participações governamentais na nova Lei do Petróleo. Rio Oil \& Gas Expo and Conference. Rio de Janeiro: 2000.

SCOTT, Anthony. The evolution of resource property rights. New York: Oxford University Press, 2008.

SEC, Securities and Exchange Comission. Disponível em: $<$ http://www.sec.gov/about/whatwedo.shtml>. Acesso em: 21 de março de 2012.

SEIXAS FILHO, Aurélio Pitanga. Natureza Jurídica da Compensação Financeira por Exploração de Recursos Minerais. In: ROCHA, Valdir de Oliveira (org.). Grandes Questões Atuais do Direito Tributário. São Paulo: Dialética, 1998.

SERRA, Rodrigo Valente. Rendas petrolíferas no Brasil: critérios de distribuição distorcidos induzem ineficiência do gasto. In: MENDES, Marcos (org.). Gasto Público Eficiente. Rio de Janeiro: Topbooks, 2006.

SERRA, Rodrigo. Contribuição para o debate acerca da distribuição dos royalties petroliferos no Brasil. Tese de doutorado. Unicamp: Campinas, 2005.

SERRA, Rodrigo et al. Royalties: ameaças às antigas regras de distribuição. Anais do XI Congresso Brasileiro de Energia. Rio de Janeiro, 2006.

SERRA, Rodrigo, PATRÃO, Carla. Impropriedades dos critérios de distribuição dos royalties no Brasil. In: PIQUET, Rosélia (org.). Petróleo, royalties e região. Rio de Janeiro, Garamond, 2003.

SERRA, Rodrigo V. TERRA, Denise T. Notas sobre a região petro-rentista da Bacia de Campos. In: CARVALHO, Ailton M. TOTTI, Maria E. Formação histórica e econômica do Norte Fluminense. Rio de Janeiro: Garamond, 2006.

SHAH, Sonia. A História do Petróleo. Tradução de Marcelo Ferroni. Porto Alegre: 
L\&PM, 2007.

SILVA, Jair Cândido. Lei n. 4.320/64 Comentada: uma contribuição para a elaboração da Lei Complementar ( $§ 9^{\circ}$ art. 165 da CF/88). Brasília: Thesaurus, 2007.

SILVA, Mauro Santos. Teoria do federalismo fiscal: notas sobre as contribuições de Oates, Musgrave, Shah e Ter-Minassian. Nova Economia 15 (1) pp. 117-137. Belo Horizonte, 2005.

SIMÕES, Ivan. Desafios Regulatórios, de Investimentos e de Demanda de Bens e Serviços. In: Seminário “Os Desafios do Pré-Sal”, 2008. Rio de Janeiro: IBP, FGV, 2008. Disponível em: $<$ http://www.ibp.org.br/main.asp?View=\{FBCBA377-C40B49B8-8BC6-FBB86F01C85C\}>. Acesso em: 9 de outubro de 2008.

SPE, Society of Petroleum Engineers; AAPG, American Association of Petroleum Geologists; WPC, World Petroleum Council; SPEE, Society of Petroleum Evaluation Engineers; SEG, Society of Exploration Geophysicists. Guide lines for Application of the Petroleum Resources Management System. Disponível em: $<$ http://www.spe.org/industry/reserves.php>. Acesso em: 21 de março de 2012.

SOUSA, Francisco José Rocha de. A cessão onerosa de áreas do pré-sal e a capitalização da Petrobras, 2011. Disponível em: $<$ http://www2.camara.leg.br/documentos-epesquisa/publicacoes/estnottec/tema16/2011_907.pdf $>$. Acesso em 23 de março de 2013.

SOUSA, Rubens Gomes de. Compêndio de Legislação Tributária, edição póstuma. São Paulo: Resenha Tributária, 1975.

SOUTO, Marcos Juruena Villela. Compensação Financeira pela Exploração de Recursos Minerais. In: IOB - Repertório de Jurisprudência: tributário, constitucional e administrativo, São Paulo, set. 2000, v. 18.

STEELE, Henry. Natural Resource Taxation: Resource Allocation and Distribution 
Implications. In: MASON, Gaffney (org.). Extractive Resources and Taxation. London: 1967.

STIGLITIZ, Joseph E. Transformando os Recursos Naturais em uma Bênção em vez de uma Maldição. In: TSALIK, S., SCHIFFRIN, A. (orgs.). Reportando o Petróleo: Um Guia Jornalístico sobre Energia e Desenvolvimento. New York: Open Society Institute, 2005 .

TAVERNE, Bernard. Petroleum, Industry and Governments: an introduction to petroleum regulation, economics and government policies. London: Kluwer Law International, 1999.

TELLES, Eduardo Maccari. A Compensação Financeira Revisitada. In: Revista Forense, Rio de Janeiro, jul./ago. 2004, v. 374.

TER-MINASSIAN, Teresa. Intergovernmental Fiscal Relations in a Macroeconomic Perspective: An Overview. In: TER-MINASSIAN, Teresa. Fiscal Federalism in Theory and Practice. Washington: International Monetary Fund, 1997.

TORRES, Heleno Taveira. A Compensação Financeira Devida pela Utilização de Recursos Hídricos, Exploração de Recursos Minerais ou Produção de Petróleo, Xisto Betuminoso e Gás Natural (art. 20, § 1º, CF) - sua Natureza Jurídica. In: ROCHA, Valdir de Oliveira (org.). Grandes Questões Atuais do Direito Tributário. São Paulo: Dialética, 1998.

TORRES, Ricardo Lobo. Curso de Direito Financeiro e Tributário. 14. ed. Rio de Janeiro: Renovar, 2007.

TRINDADE, Antônio Augusto Cançado. Direito das Organizações Internacionais. 3. ed. Belo Horizonte: Del Rey, 2003.

VIDIGAL, Geraldo de Camargo. Fundamentos do Direito Financeiro. São Paulo: Revista dos Tribunais, 1972. 
VIEGAS, Paulo Roberto Alonso. A precificação do barril enterrado de petróleo na cessão de direitos de exploração destinada à Petrobras, 2010. Disponível em: $<$ http://www.senado.gov.br/senado/conleg/textos_discussao/NOVOS\%20TEXTOS/Tex to\%2078\%20-\%20Paulo\%20Viegas.pdf>. Acesso em 23 de março de 2013.

XAVIER, Alberto. Natureza Jurídica e Âmbito de Incidência da Compensação Financeira por Exploração de Recursos Minerais. In: Revista Dialética de Direito Tributário, São Paulo, fev. 1998, v. 29. 